\title{
The Regucalcin Gene is a Key in the Therapy of Hepatocellular Carcinoma Masayoshi Yamaguchi*
}

Department of Hematology and Medical Oncology, Emory University School of Medicine, Atlanta, USA

Hepatocellular carcinoma (HCC), the most common primary liver cancer, is one of the most prevalent malignant diseases worldwide, and the third most common causes of cancer-related death [1-3]. Globally, there are approximately 750,000 new cases of HCC reported per year. The incidence of HCC is increasingly in the United States and other developed countries. Moreover, features of HCC are an aggressive cancer with a dismal outcome largely due to metastasis and postsurgical recurrence. In most cases, HCC originates on a background of cirrhosis, a chronic and diffuse hepatic disease that result from continuous liver injury and regeneration [3]. Cirrhosis is present in approximately $80 \%$ $90 \%$ of HCC patients and constitutes the largest single risk factor. In cirrhotic liver, changes in fat metabolism associated with the activation of adipocyte-like pathways are thought to be involved in neoplastic transformation [3]. Increased hepatocyte turnover, inflammation, and oxidative DNA damage is implicated in the pathogenesis of the liver disease including obesity, Type 2 diabetes, insulin resistant, and nonalcoholic fatty liver disease. The prevalent risk factors for HCC are also the cause of liver cirrhosis, and include viral infections (hepatitis B and C) and alcohol consumption; further risk factors include tobacco smoking, exposure to aflatoxin B1 and vinyl chloride, diabetes, and genetic disorders, such as hemochromatosis and alpha-1 antitrypsin deficiency [4-8].

Hepatocarcinogenesis is a multistep process initiated by external stimuli that lead to genetic changes in hepatocytes or stem cells, resulting in proliferation, apoptosis, dysplasia and neoplasia. The majority of HCC cases are also related to chronic viral infections. Hepatitis B virus (HBV) DNA integrates into the host genome, inducing chromosome instability and insertional mutations that may activate various oncogenes, such as cyclin A [9-12]. Viral proteins, in particular $\mathrm{X}$ protein $(\mathrm{HBX})$, act as transactivators to upregulate several oncogenes (such as c-myc and c-jun) and transcriptional factors (such as nuclear factor- $\mathbf{k B}$ ) [13-15]. Additionally, $\mathrm{HBx}$ activates promoters of genes encoding interleukin-8 (IL-8), tumor necrosis factor (TNF), transforming growth factor (TGF)- $\boldsymbol{\beta}$ and epidermal growth factor receptor (EGFR) [16]. HBx can also stimulate several signal transduction pathways, including the JAK/STAT, RAS/RAF/MAPK, and $\mathrm{Wnt} / \boldsymbol{\beta}$-catenin pathways $[16,17]$. The contributions of hepatitis $\mathrm{C}$ virus (HCV) to hepatocarcinogenesis are mediated through viral proteins, including core, NS3 and NS5A proteins. HCV core protein can promote apoptosis or cell proliferation through interaction with p53 or upregulation of Wnt-1 at the transcriptional level [18-20].

The prognosis of advanced HCC remains poor in spite of the development of novel therapeutic strategies [21]. Traditional therapies are not effective for HCC and are too toxic for patients with cirrhosis. Transarterial chemoembolization and radioembolization are the main treatments for intermediate-stage HCC at the present time. Improved knowledge of the oncogenic processes and signaling pathways that regulate tumor cell proliferation, differentiation, angiogenesis, invasion and metastatis has led to the identification of several potential therapeutic targets, which have driven the development of molecularly targeted therapies [21]. An ideal cancer target meets the following criteria: the target is relatively specific for cancer cells (not expressed or expressed at very low levels in normal cells but overexpressed in cancer cells) [21]. Meanwhile, overexpression of the target is associated with malignant biological phenotypes and/or poor prognosis; the target plays an essential role in cancer initiation and progression, and inhibition of expression or activity of the target induces growth suppression and/or apoptosis in cancer cells. The target is "drugable" as an enzyme (e.g., a kinase) or cell surface molecule (e.g., a membrane-bound receptor) that can be easily screened for small-molecule inhibitors or targeted by a specific antibody $[21,22]$. The only systemic therapy available for advanced HCC is based on the multikinase inhibitor sorafenib [22], which is the most effective therapeutic tool for advanced nonresectable HCC, in which it can slightly improve patient survival. The survival of patients with advanced HCC treated with sorafenib depends on the absence of liver dysfunction and on the status of the patient [23]. In the past few years, the use of sorafenib in combination with transarterial chemoembolization has improved survival rates in patients with advanced HCC. Recently, new perspectives in cancer treatment have appeared with the advent of microRNAs, a novel class of noncoding small RNAs [24].

Regucalcin, which the author discovered in 1978 [25-28], may play a pivotal role in the suppression of hepatocarcinogenesis [29$31]$. Regucalcin plays a role as a suppressor protein in various cell signal transductions [26-28]. The regucalcin gene is located on the $\mathrm{X}$ chromosome in consisting of seven exons and six introns [32]. Regucalcin (RGN) and its gene ( $r g n)$ are identified in over 15 species consisting of regucalcin family and the gene species are highly conserved in vertebrate species [32]. The regucalcin gene expression is regulated through various transcription factors (including AP-1, NF1-A1, RGPR-p117, $\beta$-catenin, SP1 and others), which are identified as the enhancer and suppressor, and this expression is regulated with hormonal stimulation and physiological state [32]. Regucalcin plays a pivotal role as a suppressor protein in various signal transductions to maintain cell homeostasis for stimuli, and it plays a multifunctional role in cell regulation through maintaining of intracellular $\mathrm{Ca}^{2+}$ homeostasis and suppressing of signal transduction in various cell types [26-28]. Interestingly, the cytoplasmic regucalcin is translocated into the nucleus and inhibits nuclear $\mathrm{Ca}^{2+}$-dependent and -independent protein kinases and protein phosphatases, $\mathrm{Ca}^{2+}$-activated endonuclease, and DNA and RNA synthesis [33].

Regucalcin has been demonstrated to play a role as a suppressor protein in cell proliferation, which is mediated through various signaling stimulations, in the cloned normal rat kidney proximal

*Corresponding author: Masayoshi Yamaguchi, PhD, Department of Hematology and Medical Oncology, Emory University School of Medicine, 1365 C Clifton Road, NE, Atlanta, GA 30322, USA, E-mail: yamamasa1155@yahoo.co.jp

Received January 20, 2014; Accepted January 23, 2014; Published January 27 2014

Citation: Yamaguchi M (2014) The Regucalcin Gene is a Key in the Therapy of Hepatocellular Carcinoma. J Cancer Sci Ther 6: e132. doi:10.4172/19485956.1000e132

Copyright: ( 2014 Yamaguchi M. This is an open-access article distributed under the terms of the Creative Commons Attribution License, which permits unrestricted use, distribution, and reproduction in any medium, provided the original author and source are credited. 
tubular epithelial NRK52E cells and the cloned rat hepatoma H4-II-E cells $[31,34,35]$. Regucalcin causes G1 and G2/M phase cell cycle arrest in these cells $[31,36]$. The anti-cell proliferation effect of regucalcin is not dependent on apoptosis; regucalcin suppresses apoptosis induced through multisignaling pathway [37]. Molecular mechanisms by which regucalcin suppresses the promotion of cell proliferation have been elucidated. Regucalcin, which is expressed through signaling factors that stimulate cell proliferation, is translocated into the nucleus with mechanism by which is mediated through protein kinase C-dependent signaling [31,34]. Regucalcin directly inhibits the activities of various $\mathrm{Ca}^{2+} /$ calmodulin-dependent enzymes, protein kinases and protein phosphatases in the cytoplasm and nuclei [27,28,31]. Regucalcin inhibits nuclear DNA and RNA synthesis, and it has suppressive effects on the expression of $c-m y c, H a-r a s$, and $c-s r c \mathrm{mRN}$, which are tumorstimulator genes and also stimulates the expression of $p 53$ and $R b$ mRNAs that are tumor-suppressor genes [31,38]. Moreover, regucalcin inhibits protein synthesis and stimulates protein degradation due to inhibiting aminoacyl-tRNA synthetase and activating cysteinyl protease $[27,28]$. Thus, suppressive effects of regucalcin on cell proliferation are mediated through the suppression of many cell signaling processes including the suppression of oncogene expression and stimulation of tumor suppressor gene expression in liver cells $[31,33,38]$.

Noticeably, the regucalcin gene and its protein levels have been found to specifically suppress in human hepatocellular carcinoma (HCC) using analysis with multiple gene expression profiles and proteomics [39-43]. The suppression of regucalcin gene expression has been shown to occur at earlier periods of carcinogenesis in rats treated with diethylnitrosamine and then 2-acetylaminofluorene combined with partial hepatectomy, which induces an increase in proliferating cells [29]. The suppression of regucalcin protein expression has also been identified in proteomic analysis that was differentially expressed in the livers of rats fed 5\% ethanol for 1 and 3 months [30]. In addition, regucalcin mRNA expression is suppressed by disorder of liver metabolism (including carbon tetrachloride [44], galactosamine [45] and phenobarbital [46] administration, the conditions of diabetes and ethanol ingestion [47]), which may lead to cirrhosis and HCC. The suppression of regucalcin gene expression may lead to the development of HCC.

Regucalcin, a suppressor protein in cell signaling system, may play a role as a key molecule in the depression of cell proliferation and carcinogenesis of various tissues and cell types. Overexpression of regucalcin in cancer cells may play preventive and therapeutic roles in carcinogenesis. The development of a novel gene therapy with the regucalcin gene deliver system will be expected in clinical aspects.

\section{Acknowledgements}

Regucalcin studies of the author were supported by a Grant-in-Aid for Scientific Research (C) No.63571053, No.02671006, No.04671362, No.06672193, No.08672522, No.10672048, No.13672292 and No.17590063 from the Ministry of Education, Science, Sports, and Culture, Japan. Also, the author (MY) was awarded the Bounty of Encouragement Foundation in Pharmaceutical Research, Japan and the Bounty of the Yamanouchi Foundation for Research on Metabolic Disorders, Japan. This study was also supported by the Foundation for Biomedical Research on Regucalcin.

\section{References}

1. Jemal A, Center MM, DeSantis C, Ward EM (2010) Global patterns of cancer incidence and mortality rates and trends. Cancer Epidemiol Biomarkers Prev 19: 1893-1907.

2. Bosch FX, Ribes J, Díaz M, Cléries R (2004) Primary liver cancer: worldwide incidence and trends. Gastroenterology 127: S5-5S16.
3. Bosch FX, Ribes J, Cléries R, Díaz M (2005) Epidemiology of hepatocellular carcinoma. Clin Liver Dis 9: 191-211, v.

4. Farazi PA, DePinho RA (2006) Hepatocellular carcinoma pathogenesis: from genes to environment. Nat Rev Cancer 6: 674-687.

5. Purohit V, Rapaka R, Kwon OS, Song BJ (2013) Roles of alcohol and tobacco exposure in the development of hepatocellular carcinoma. Life Sci 92: 3-9.

6. Wu HC, Santella R (2012) The role of aflatoxins in hepatocellular carcinoma Hepat Mon 12: e7238.

7. Starley BQ, Calcagno CJ, Harrison SA (2010) Nonalcoholic fatty liver disease and hepatocellular carcinoma: a weighty connection. Hepatology 51: 1820 1832.

8. Dragani TA (2010) Risk of HCC: genetic heterogeneity and complex genetics J Hepatol 52: 252-257

9. Terasaki S, Kaneko S, Kobayashi K, Nonomura A, Nakanuma Y (1998) Histological features predicting malignant transformation of nonmalignant hepatocellular nodules: a prospective study. Gastroenterology 115: 1216-1222.

10. Brechot C, Pourcel C, Louise A, Rain B, Tiollais P (1980) Presence of integrated hepatitis $B$ virus DNA sequences in cellular DNA of human hepatocellular carcinoma. Nature 286: 533-535.

11. Minami M, Daimon $Y$, Mori $K$, Takashima H, Nakajima T, et al. (2005) Hepatitis $B$ virus-related insertional mutagenesis in chronic hepatitis $B$ patients as an early drastic genetic change leading to hepatocarcinogenesis. Oncogene 24 4340-4348.

12. Wang J, Chenivesse X, Henglein B, Bréchot C (1990) Hepatitis B virus integration in a cyclin A gene in a hepatocellular carcinoma. Nature 343: 555557

13. Balsano C, Avantaggiati ML, Natoli G, De Marzio E, Will H, et al. (1991) Fulllength and truncated versions of the hepatitis $B$ virus (HBV) $X$ protein $(p X)$ transactivate the cmyc protooncogene at the transcriptional level. Biochem Biophys Res Commun 176: 985-992.

14. Twu JS, Lai MY, Chen DS, Robinson WS (1993) Activation of protooncogene C-jun by the X protein of hepatitis B virus. Virology 192: 346-350.

15. Chirillo P, Falco M, Puri PL, Artini M, Balsano C, et al. (1996) Hepatitis B virus $\mathrm{pX}$ activates NF-kappa B-dependent transcription through a Raf-independent pathway. J Virol 70: 641-646.

16. Andrisani OM, Barnabas $S$ (1999) The transcriptional function of the hepatitis $B$ virus $X$ protein and its role in hepatocarcinogenesis (Review). Int $\mathrm{J}$ Oncol 15: $373-379$

17. Cha MY, Kim CM, Park YM, Ryu WS (2004) Hepatitis B virus X protein is essential for the activation of Wnt/beta-catenin signaling in hepatoma cells. Hepatology 39: 1683-1693.

18. Yamanaka T, Kodama T, Doi T (2002) Subcellular localization of HCV core protein regulates its ability for p53 activation and p21 suppression. Biochem Biophys Res Commun 294: 528-534.

19. Fukutomi T, Zhou Y, Kawai S, Eguchi H, Wands JR, et al. (2005) Hepatitis C virus core protein stimulates hepatocyte growth: correlation with upregulation of wnt-1 expression. Hepatology 41: 1096-1105.

20. Florese RH, Nagano-Fujii M, Iwanaga $Y$, Hidajat R, Hotta H (2002) Inhibition of protein synthesis by the nonstructural proteins NS4A and NS4B of hepatitis C virus. Virus Res 90: 119-131.

21. Shin JW, Chung YH (2013) Molecular targeted therapy for hepatocellular carcinoma: current and future. World J Gastroenterol 19: 6144-6155.

22. Wilhelm SM, Adnane L, Newell P, Villanueva A, Llovet JM, et al. (2008) Preclinical overview of sorafenib, a multikinase inhibitor that targets both Raf and VEGF and PDGF receptor tyrosine kinase signaling. Mol Cancer Ther 7 : 3129-3140.

23. Singal AG, Marrero JA (2010) Recent advances in the treatment of hepatocellular carcinoma. Curr Opin Gastroenterol 26: 189-195

24. Callegari E, Elamin BK, Sabbioni S, Gramantieri L, Negrini M (2013) Role of microRNAs in hepatocellular carcinoma: a clinical perspective. Onco Targets Ther 6: 1167-1178

25. Yamaguchi M, Yamamoto $T$ (1978) Purification of calcium binding substance from soluble fraction of normal rat liver. Chem Pharm Bull (Tokyo) 26: 19151918. 
Citation: Yamaguchi M (2014) The Regucalcin Gene is a Key in the Therapy of Hepatocellular Carcinoma. J Cancer Sci Ther 6: e132. doi:10.4172/19485956.1000 e132

Page 3 of 3

26. Yamaguchi $\mathrm{M}$ (1992) A novel $\mathrm{Ca}^{2+}$-binding protein regucalcin and calcium inhibition. Regulatory role in liver cell function. In: K Kohama (ed.) Calcium Inhibition. Japan Sci Soc Press, Tokyo and CRC Press, Boca Raton, USA $19-41$.

27. Yamaguchi M (2005) Role of regucalcin in maintaining cell homeostasis and function (review). Int J Mol Med 15: 371-389.

28. Yamaguchi M (2011) Regucalcin and cell regulation: role as a suppressor protein in signal transduction. Mol Cell Biochem 353: 101-137.

29. Suzuki S, Asamoto M, Tsujimura K, Shirai T (2004) Specific differences in gene expression profile revealed by cDNA microarray analysis of glutathione S-transferase placental form (GST-P) immunohistochemically positive rat liver foci and surrounding tissue. Carcinogenesis 25: 439-443.

30. Fernando H, Wiktorowicz JE, Soman KV, Kaphalia BS, Khan MF et al. (2013) Liver proteomics in progressive alcoholic steatosis. Toxicol Appl Pharmacol 266: 470-480.

31. Yamaguchi M (2013) Suppressive role of regucalcin in liver cell proliferation: involvement in carcinogenesis. Cell Prolif 46: 243-253.

32. Yamaguchi $M$ (2011) The transcriptional regulation of regucalcin gene expression. Mol Cell Biochem 346: 147-171.

33. Yamaguchi M (2013) Role of regucalcin in cell nuclear regulation: involvement as a transcription factor. Cell Tissue Res 354: 331-341.

34. Nakagawa T, Yamaguchi M (2006) Overexpression of regucalcin enhances its nuclear localization and suppresses L-type $\mathrm{Ca} 2+$ channel and calcium-sensing receptor mRNA expression in cloned normal rat kidney proximal tubular epithelial NRK52E cells. J Cell Biochem 99: 1064-1077.

35. Misawa H, Inagaki S, Yamaguchi M (2001) Suppression of cell proliferation and deoxyribonucleic acid synthesis in the cloned rat hepatoma H4-II-E cells overexpressing regucalcin. J Cell Biochem 84: 143-149.

36. Yamaguchi M, Daimon $Y(2005)$ Overexpression of regucalcin suppresses cell proliferation in cloned rat hepatoma H4-II-E cells: Involvement of intracellula signaling factors and cell cycle-related genes. J Cell Biochem 95: 1169-1177.
37. Yamaguchi M (2013) The anti-apoptotic effect of regucalcin is mediated through multisignaling pathways. Apoptosis 18: 1145-1153.

38. Tsurusaki Y, Yamaguchi M (2003) Overexpression of regucalcin modulates tumor-related gene expression in cloned rat hepatoma H4-II-E cells. J Cell Biochem 90: 619-626.

39. Graveel CR, Jatkoe T, Madore SJ, Holt AL, Farnham PJ (2001) Expression profiling and identification of novel genes in hepatocellular carcinomas. Oncogene 20: 2704-2712.

40. Choi JK, Choi JY, Kim DG, Choi DW, Kim BY, et al. (2004) Integrative analysis of multiple gene expression profiles applied to liver cancer study. FEBS Lett 565: 93-100.

41. Blanc JF, Lalanne C, Plomion C, Schmitter JM, Bathany K, et al. (2005) Proteomic analysis of differentially expressed proteins in hepatocellular carcinoma developed in patients with chronic viral hepatitis C. Proteomics 5: 3778-3789.

42. Roy L, Laboissière S, Abdou E, Thibault G, Hamel N, et al. (2010) Proteomic analysis of the transitional endoplasmic reticulum in hepatocellular carcinoma: an organelle perspective on cancer. Biochim Biophys Acta 1804: 1869-1881.

43. Schröder PC, Segura V, Riezu JI, Sangro B, Mato JM, et al. (2011) A signature of six genes highlights defects on cell growth and specific metabolic pathways in murine and human hepatocellular carcinoma. Funct Integr Genomics 11: 419-429.

44. Isogai M, Shimokawa N, Yamaguchi M (1994) Hepatic calcium-binding protein regucalcin in released into the serum of rats administered orally carbon tetrachloride. Mol Cell Biochem 131: 173-179.

45. Isogai M, Oishi K, Yamaguchi M (1994) Serum release of hepatic calciumbinding protein regucalcin by liver injury with galactosamine administration in rats. Mol Cell Biochem 136: 85-90.

46. Isogai M, Oishi K, Shimokawa N, Yamaguchi M (1994) Expression of hepatic calcium-binding protein regucalcin mRNA is decreased by phenobarbital administration in rats. Mol Cell Biochem 141: 15-19.

47. Isogai M, Kurota H, Yamaguchi M (1997) Hepatic calcium-binding protein regucalcin concentration is decreased by streptozotocin-diabetic state and ethanol ingestion in rats. Mol Cell Biochem 168: 67-72. 